\title{
Effects of using inclined parametric echosounding on sub-bottom acoustic imaging and advances in buried object detection
}

\author{
Jens Schneider von Deimling ${ }^{1,3,4} \cdot$ Philipp Held $^{1} \cdot$ Peter Feldens $^{2} \cdot$ Dennis Wilken $^{3}$
}

Received: 8 July 2015 / Accepted: 2 December 2015 /Published online: 9 December 2015

(C) The Author(s) 2015. This article is published with open access at Springerlink.com

\begin{abstract}
This study reports an adaptation of a parametric echosounder system using $15 \mathrm{kHz}$ as secondary frequency to investigate the angular response of sub-bottom backscatter strength of layered mud, providing a new method for enhanced acoustic detection of buried targets. Adaptions to achieve both vertical $\left(0^{\circ}\right)$ and non-vertical inclination $(1-$ $15^{\circ}, 30^{\circ}, 45^{\circ}$ and $60^{\circ}$ ) comprise mechanical tilting of the acoustic transducer and electronic beam steering. Data were acquired at $18 \mathrm{~m}$ water depth at a study site characterized by a flat, muddy seafloor where a $0.1 \mathrm{~m}$ diameter power cable lies $1-2 \mathrm{~m}$ below the seafloor. Surveying the cable with vertical incidence revealed that the buried cable can hardly be discriminated against the backscatter strength of the layered mud. However, the backscatter strength of layered mud decreases strongly at $>3 \pm 0.5^{\circ}$ incidence and the layered mud echo pattern vanishes beyond $5^{\circ}$. As a consequence, the backscatter pattern of the buried cable is very pronounced in acoustic images gathered at $15^{\circ}, 30^{\circ}, 45^{\circ}$ and $60^{\circ}$ incidence. The size of the cable echo pattern increases linearly with incidence. These effects are attributed to reflection loss from layered mud at larger incidence and to the scattering of the $0.1 \mathrm{~m}$ diameter buried cable. Data analyses support the visual
\end{abstract}

Jens Schneider von Deimling

jschneider@geomar.de; jschneider@geophysik.uni-kiel.de

1 GEOMAR Helmholtz Centre for Ocean Research Kiel, Wischhofstr. 1-3, 24148 Kiel, Germany

2 Leibniz Institute for Baltic Sea Research Warnemünde, Seestrasse 15, 18119 Warnemünde, Germany

3 Institute of Geosciences, Christian-Albrechts-Universität zu Kiel, Otto-Hahn Platz 1, 24118 Kiel, Germany

4 Present address: Christian-Albrechts-Universität zu Kiel, Otto-Hahn-Platz 1, Kiel 24118, Germany impression of superior detection of the cable with an up to 2.6-fold increase of the signal-to-noise ratio at $40^{\circ}$ incidence compared to the vertical incidence case.

\section{Introduction}

Anthropogenic offshore activities on the seabed will grow significantly in the future due to increasing requests for marine renewable energy, raw material exploitation and associated infrastructure requirements. During their initial planning phase and during operation, such ventures require efficient remote sensing techniques for investigating the seabed in terms of stratigraphy, geomorphology, seabed classification and habitat mapping, sediment dynamics and buried objects.

Sub-bottom echosounders currently represent the state-ofthe-art systems for investigating the upper 1-100 $\mathrm{m}$ below the seafloor (bsf). Parametric echosounders combine the benefits of high resolution and high penetration with narrow beam width. They offer higher resolution with smaller transducers compared to conventional sub-bottom echosounders (Novikov et al. 1987). Mobile parametric transducers are available with, for example, primary frequencies between 90 and $105 \mathrm{kHz}$ and allow penetration depths of the secondary frequency (between 5 and $15 \mathrm{kHz}$ ) up to $50 \mathrm{~m}$ (Wunderlich et al. 2005) with corresponding range resolutions in the centimetre to decimetre scale.

State-of-the-art sub-bottom echosounding is preferentially performed at normal incidence (angle between acoustic beam and seafloor is perpendicular) to the seafloor to achieve maximum sound penetration and to optimise coherent sediment layer reflection. This is the method of choice for geological surveys and stratigraphic mapping (Rostek et al. 1991). However, many applications such as underwater archaeology (Wunderlich et al. 2005). cable and pipeline inspection, 
construction work or naval mine hunting are concerned with the detection of shallow buried objects. Point targets may cause diffraction hyperbolae in omnidirectional seismic sources. Their precise location cannot easily be determined with 2D systems, and the application of 3D seismic systems requires much effort. While the narrow footprint of parametric systems increases the horizontal resolution, it also decreases the occurrence of diffraction hyperbolae from small objects. Coherent reflections from geological layers may obscure the detection of buried targets during acoustic surveys with normal incidence. To overcome this limitation, Wunderlich et al. (2005) used a non-vertical $\left(30^{\circ}\right)$ beam incidence within a study of archaeological settlement remnants. Other studies employed non-vertical incidence acoustic setups to map sediment coverage (Mitchell 1993) and shallow gas (Schneider von Deimling et al. 2013). Szender and Kosalos (1997) and Leighton and Evans (2008) presented bistatic (spatially separated acoustic source and receiver) approaches to track underwater cables. Maguer et al. (2000) showed experimentally that incidence between of $15^{\circ}$ and $30^{\circ}$ can be useful for subbottom investigations. Especially for naval mine hunting, sophisticated techniques were developed for enhanced detection of buried targets by towed low-frequency arrays (Jans et al. 2012). including the synthetic aperture sonar (SAS) approach (Piper 2001; Schock 2008) or 3D seismic systems (Vardy et al. 2008). The drawback is that those very high-resolution systems need to be towed and require sophisticated navigation systems and transducers exceeding $1 \mathrm{~m}$ in size, making their application time consuming and expensive.

In this study, a lightweight parametric sonar is combined with mechanic rotation and electronic beam steering to achieve a versatile non-vertical low-frequency acoustic setup. The aim of the study is twofold: (1) to evaluate how the angular backscatter of layered mud changes with increasing incidence and (2) to test whether a cable buried in layered mud can be detected better using non-vertical incidence.

\section{Geological setting}

The study area is located in the western Baltic Sea (Germany) in the outer part of the Kiel Fjord (Fig. 1) in approximately 18 $\mathrm{m}$ water depth and $8 \mathrm{~km}$ offshore. Kiel Fjord is a former glacial meltwater channel. The uppermost 2 to $5 \mathrm{~m}$ of sediments consist of organic-rich mud underlain by a morainic till (Hinz et al. 1971; Schwarzer and Themann 2003). Towards the coastline the sediments become coarser-grained.

The mud in the survey area was previously characterized with an attenuation coefficient $\alpha$ of $0.1-0.2 \mathrm{~dB} \mathrm{~m}^{-1} \mathrm{kHz}^{-1}$ (Jackson and Richardson 2007). resulting in high acoustic transparency. Sound velocity in the upper layers of the mud is very similar to or lower than the seismic velocity of seawater (Jackson and Richardson 2007; Schneider von Deimling

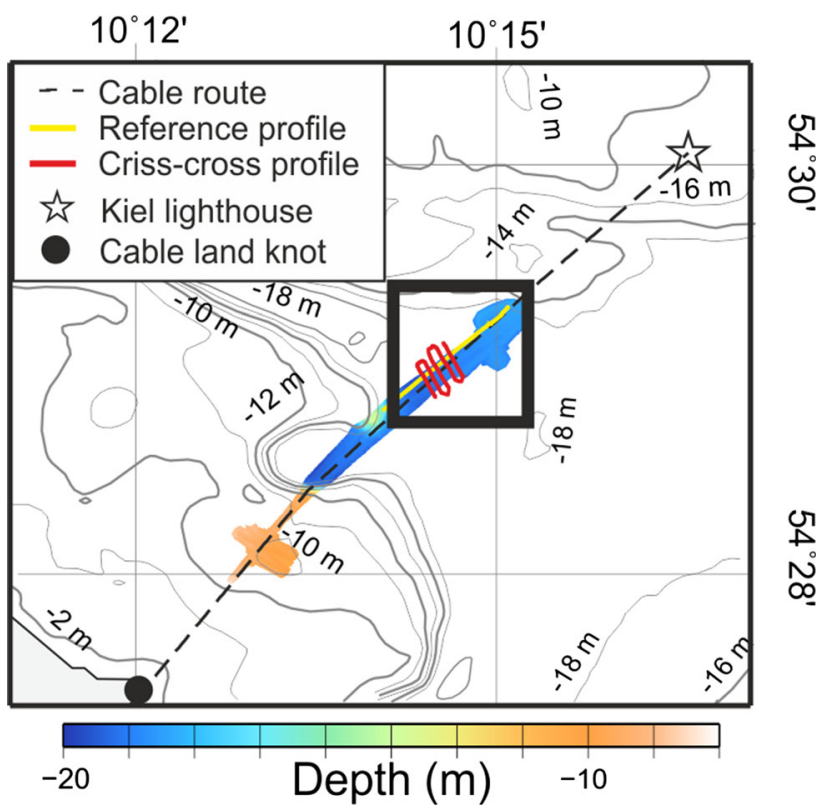

Fig. 1 Overview chart showing the research area (square), as well as the locations of the approximate cable route, a nearby reference profile, and one (of 65 in all) example criss-cross profiles

et al. 2013). An area with homogeneously distributed mud was chosen for the present study.

\section{Materials and methods}

Data were acquired in March 2014 during very calm weather. First, the survey area was mapped by means of an ELAC Seabeam 1185 multibeam echosounder at $180 \mathrm{kHz}$, supported by a dual antenna CODAOCTOPUS F185 inertial navigation and motion reference unit for real time beam roll compensation, positioning and heading. Then, sub-bottom imaging was performed using an INNOMAR SES 2000 parametric echosounder (Wunderlich et al. 2005) with navigation and ship motion data from the CODA OCTOPUS system. Nautical charts served to position a 1-2 m deep buried cable (type NKRGby with three $25 \mathrm{~mm}$ copper wires surrounded by a DÜKER $100 \mathrm{~mm}$ diameter metal sheathing). The approximate cable route was criss-crossed with speeds varying between 1.7 and 4.7 knots (Fig. 1). The echosounder transmitted primary frequencies of 92.5 and $107.5 \mathrm{kHz}$, resulting in a secondary parametric difference frequency of $15 \mathrm{kHz}$ with a corresponding wavelength of $0.1 \mathrm{~m}$ (approximated by the ratio of $1,500 \mathrm{~m} \mathrm{~s}^{-1}$ sound velocity and $15 \mathrm{kHz}$ signal). The acoustic array generates a narrow $\pm 1.8^{\circ}, 3 \mathrm{~dB}$ transmit beam for primary and secondary frequencies, whereas the $3 \mathrm{~dB}$ receive beam width for the low secondary frequency is $\pm 12.3^{\circ}$. The advantage of a parametric system is that a small array is sufficient to generate narrow low-frequency beams having high horizontal and vertical resolution and very little side lobe 
cross-talk. For further technical information, the reader is referred to Wunderlich et al. (2005) and Wunderlich (2007).

Different sound transmission angles (inclinations) were generated with a rotatable flange and the electronic array beam-steering functionality (Fig. 2). The electronic beamsteering functionality of the system offers $\pm 15^{\circ}$ inclination. Combined with a maximum of $45^{\circ}$ mechanical rotation by the flange, a maximum $60^{\circ}$ inclination towards starboard was possible. To manipulate the motion data in real time, a $\mathrm{C}++$ software was developed which superimposes a sinusshaped signal on the ship roll data, forcing the sound beam to scan from $-15^{\circ}$ to $+15^{\circ}$ in steps of $1^{\circ}$. The transmit beam was stabilized in reference to a horizontal plane compensating for ship motion. Together with the multibeam bathymetric slope data and stabilized beam inclination, this enabled to assess the resulting incidence of the sound on the seabed.

The enveloped two way travel time series of $15 \mathrm{kHz}$ backscatter strength data was exported to the SEG-Y format using the INNOMAR ISE software, and visualized by colour-coded echograms using the SEISMIC UNIX open source software (Stockwell 1999). The non-calibrated echosounder delivers dimensionless backscatter strength amplitude values $\sigma$ which were corrected with a time varying gain to account for geometrical spreading and acoustic absorption. The cable showed as a positive backscatter strength anomaly in the echograms. Using a reference window over 100 successive pings symmetrically placed around each cable detection, the vertical length of the reference window was adjusted to cover the range of the corresponding echograms. The backscatter strength within these reference windows served to calculate the mean and the standard deviation of $\sigma$, the integrated backscatter strength $\sigma_{\mathrm{w}}$, as well as the integrated backscattered energy $\Sigma_{\mathrm{W}}$ which is proportional to $\sigma^{2}$. The average plus three times the standard deviation contour line was defined as the threshold for a cable echo pattern. The area enclosed by this contour line was used to derive the size of the cable echo pattern as well as to

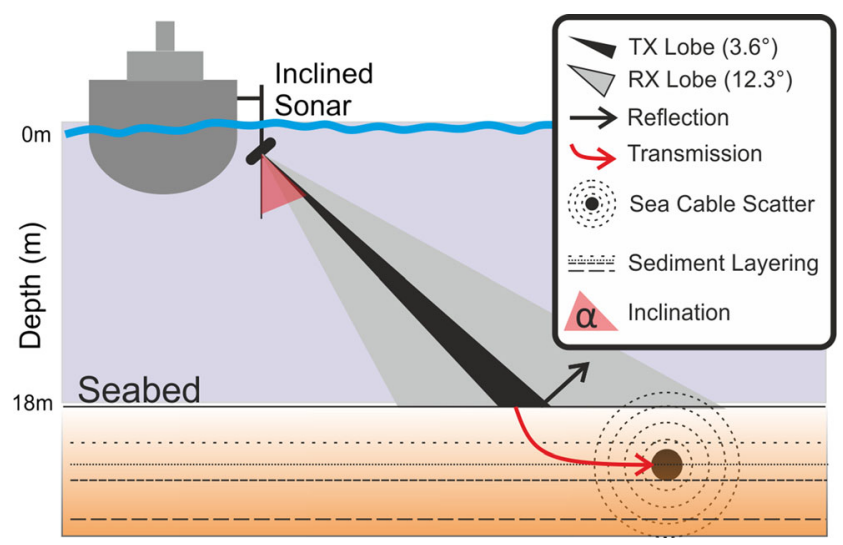

Fig. 2 Illustration of the measurement setup with inclined sonar to manipulate the seabed sound incidence. Note the sonar characteristics with different width of transmit (TX) and receive (RX) beams, and prolonged beam width on the seabed at higher incidence calculate the cable integrated backscatter strength $\sigma_{\mathrm{O}}$ and the integrated backscattered energy of the cable $\Sigma_{\mathrm{O}}$. The integrated backscattered energies served to calculate the signal-tonoise ratio $S N R=\frac{\sum_{\mathrm{o}}}{\sum_{\mathrm{w}}}$. Both the SNR and the echo pattern size in the echogram are here used for an object detection performance assessment.

\section{Results}

\section{Reference survey}

The seafloor in the northeast sector of the study area is flat and featureless with $18 \mathrm{~m}$ water depth and maximum slope values of $0.5^{\circ}$ (Fig. 1, square). Towards the southwest, a morphological high rises to approximately $15 \mathrm{~m}$ depth. Water depth shoals to less than $10 \mathrm{~m}$ towards the southwest. According to the gentle slope in the working area, sound transmit inclination transforms into seabed incidence with an error of $\pm 0.5^{\circ}$ due to slope. Changes between transmit inclination and seabed incidence by sound refraction are negligible due to the very small differences of only $6 \mathrm{~m} \mathrm{~s}^{-1}$ in sound velocity in the water column.

Calculating an echogram using the sweep technique in the vicinity of the cable area (Fig. 1) served to evaluate the angular backscatter strength response of the seabed and sub-bottom. Figure 3 represents the acoustic image gathered with sweep change of inclination over time with $1^{\circ}$ step interval ranging between $-15 \pm 0.5^{\circ}$ (Fig. 3, left side), $0 \pm 0.5^{\circ}$ (Fig. 3, ping $\# 750$ ) and $+15 \pm 0.5^{\circ}$ seabed incidence.

In the centre of Fig. 3 ( $\sim$ ping \#750), the acoustic image shows normal incidence $\left(0^{\circ}\right)$ data with distinct horizontal sub-bottom layering between 27 and $34 \mathrm{~ms}$ two way travel time (TWT). This acoustic layering data pattern is hereafter termed "layer reverberation". The mud is underlain by the till typical for the area (Schwarzer and Themann 2003). and is visible as a horizontal sub-bottom reflector at $34 \mathrm{~ms}$ TWT.

Towards higher incidence (from ping \#750 to the left and right in Fig. 3), the echogram reveals a strong decrease of layer reverberation within the mud. The effect of higher incidence can be observed at $3^{\circ}$, and backscattering from the mud disappears beyond $5^{\circ}$. Other profiles (not shown) have in common the progressive decrease of backscatter strength with higher incidence. In comparison, backscatter strengths of the seafloor surface $(\sim 26 \mathrm{~ms}$ TWT) and the till layer $(\sim 34 \mathrm{~ms}$ TWT) decrease much less and remain visible until about $15^{\circ}$.

\section{Cable survey at $0^{\circ}, 15^{\circ}, 30^{\circ}, 45^{\circ}, 60^{\circ}$}

The 65 sub-bottom profiles were recorded perpendicular to the southwest-northeast aligned cable (Fig. 1). The buried cable is located in the same geological setting as the reference 


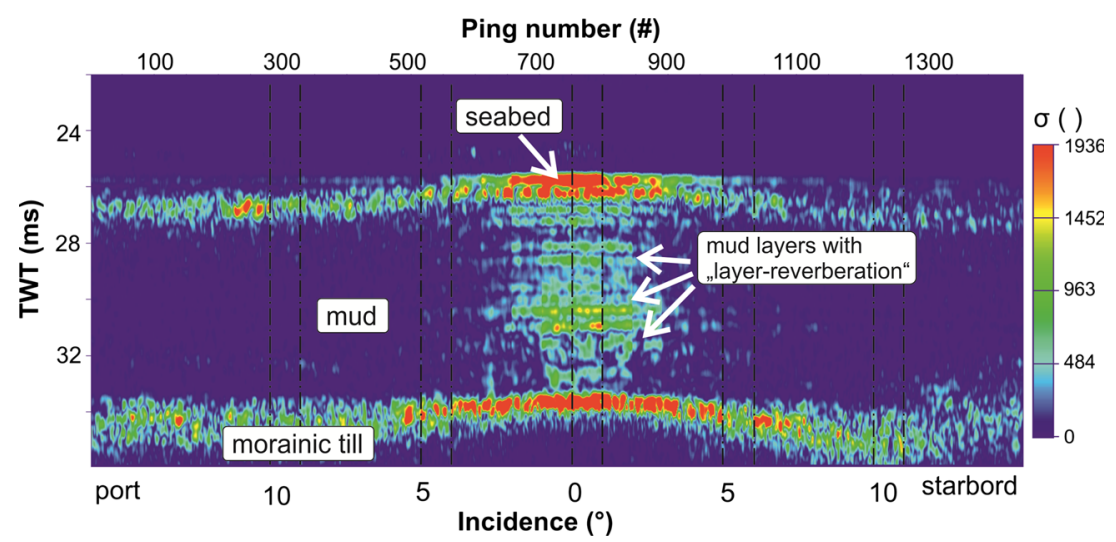

Fig. 3 Reference survey (cf. Fig. 1) recorded with the $15 \mathrm{kHz}$ secondary frequency of the Innomar SES2000 standard, showing the dimensionless backscatter strength $\sigma$. Note that the sweep causes a two way travel time

survey. To test the decrease of layer reverberation with increasing incidence, the survey lines were run with $0^{\circ}, 15^{\circ}$, $30^{\circ}$ and $45^{\circ}$ sound transmit inclination.

\section{Backscattering angular response}

At normal incidence $\left(0^{\circ}\right)$, the seafloor and sub-bottom sediment layers in the vicinity of the cable appear as bright reflectors in the echograms (Fig. $4 \mathrm{a}, 0^{\circ}$ panel) and are associated with layer reverberations. The backscatter strength of the cable at normal incidence has a magnitude very similar to the
(TWT) increase towards larger inclination which is visible through a slight bending of the seabed surface and the sub-bottom layers. Vertical lines mark the $1^{\circ}$ step inclination intervals

ambient layer reverberation, and discrimination between the two is difficult (Fig. $4 \mathrm{a}, 0^{\circ}$ panel).

Increasing inclination to $15^{\circ}, 30^{\circ}, 45^{\circ}$ or $60^{\circ}$ leads to a much more distinct appearance of the cable (Fig. 4). The backscatter strengths of the seafloor and the sub-bottom layers strongly decrease with increasing incidence (Fig. $4 \mathrm{a}$, from $0^{\circ}$ to $60^{\circ}$ panels). At angles of $45^{\circ}$ and $60^{\circ}$, the seafloor echo is no longer discernible. Maximum backscatter derived from the till layer at $34 \mathrm{~ms}$ TWT (Fig. 4a, $0^{\circ}$ panel) also declines at greater incidence, but it remains visible in the echograms until $30^{\circ}$ (Fig. $3 \mathrm{a}, 30^{\circ}$ panel). The quantitative values $\sigma_{\mathrm{W}}$ and $\sigma_{\mathrm{O}}$
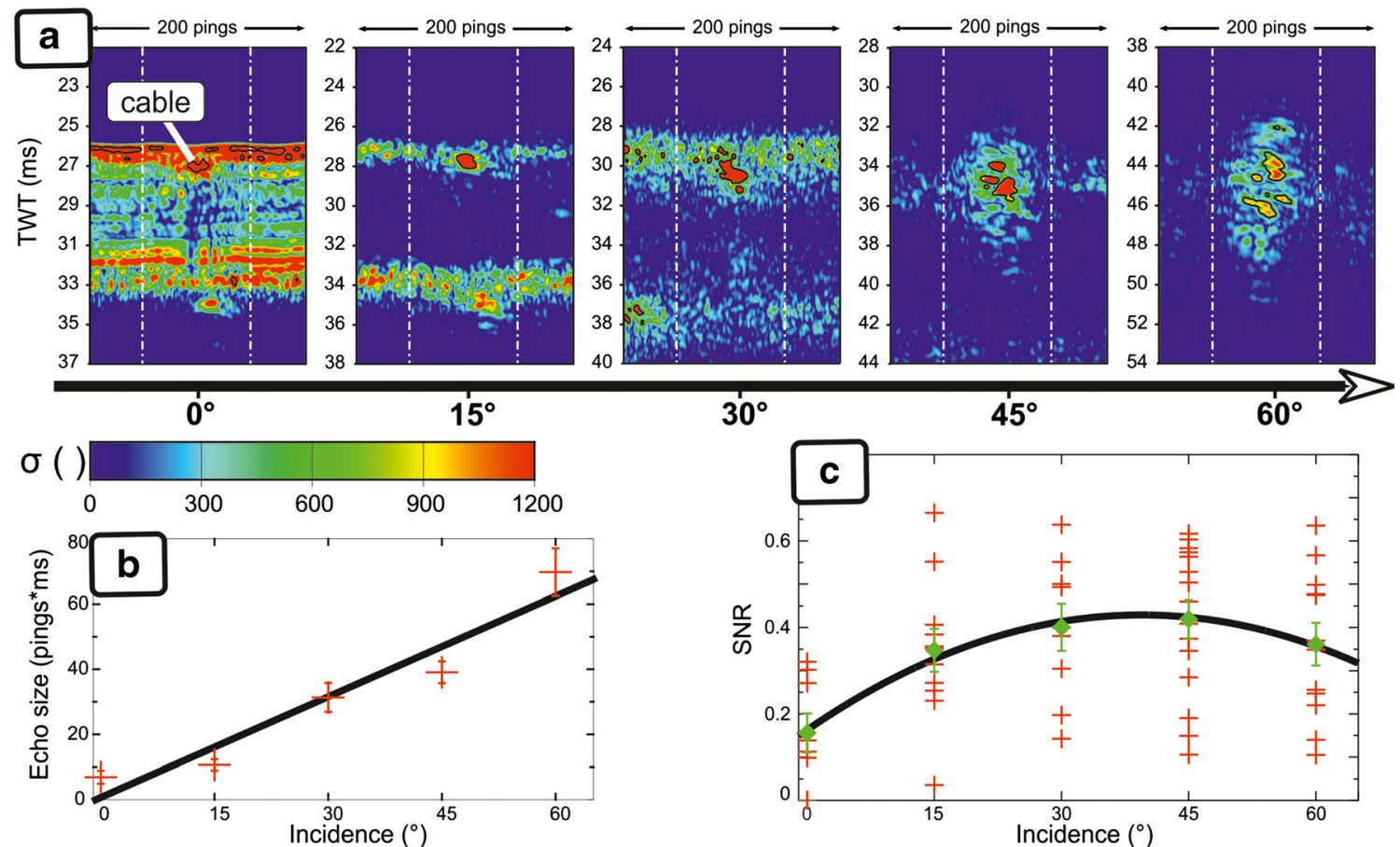

Fig. 4 a Echograms showing the buried cable at $0^{\circ}, 15^{\circ}, 30^{\circ}, 45^{\circ}$ and $60^{\circ}$ incidences, and the corresponding $\sigma_{\mathrm{W}}$ and $\sigma_{\mathrm{O}}$ values. Vertical lines Reference window. Note that the two way travel time (y-axis) arrival of the cable changes due to geometric effects when angles are varied. Incidence (arrow) increases from $0^{\circ}$ to $60^{\circ}$. b Echo pattern size versus

sound incidence and linear regression (line). c SNRs versus incidence (red crosses) and mean values (green diamonds). The black curve is fitted to the mean values and indicates a SNR maximum for an incidence of $40^{\circ}$ 
confirm the first impression of a strong decay of backscatter strength with increasing incidence. The strongest decrease of $\sigma_{\mathrm{W}}$ was found between normal incidence and $30^{\circ}$, where the remaining $\sigma_{\mathrm{W}}$ is reduced by $97 \%$. In contrast, the cable echo backscatter strength decays by only $91 \%$ between $0^{\circ}$ and $30^{\circ}$.

\section{Echo pattern size of cable}

In contrast to the angular backscatter strength response, the cable echo pattern size (cable-related backscatter strength anomaly) increases with incidence (Fig. 4b). The cable echo pattern becomes larger in both dimensions, i.e. the number of pings at which the cable was detected as well as the length of the cable echo. For example, the cable was hit by 16 successive pings and the echo length was on average $0.1 \mathrm{~ms}$ at $0^{\circ}$ incidence, whereas it was hit by 40 successive pings with an echo length on average of $3.2 \mathrm{~ms}$ at $60^{\circ}$ incidence (Fig. $4 \mathrm{a}$ ), although the survey speed and ping rate were kept constant. The size of the cable echo pattern correlates linearly with the angle of incidence. (Fig. 4b).

\section{SNR of cable}

The SNR of the cable shows a parabolic dependence on the angle of incidence (Fig. 4c). The SNR's mean value increases from 0.16 at $0^{\circ}$ up to 0.42 at $45^{\circ}$ and subsequently decreases to 0.36 at $60^{\circ}$. A curve fitted to the mean SNR values peaks at a maximum SNR of 0.43 at an incidence of $40^{\circ}$. This is 2.6 times higher than in the case of normal incidence.

\section{Discussion}

\section{Loss of layer reverberation by reflection loss}

Qualitative and quantitative analyses of the backscatter angular response from the seabed and the sub-bottom demonstrate that inclined echosounding efficiently supresses layer reverberation (Fig. 3) in the acoustic data and thus increases the detection performance of the buried cable (Fig. 4). The reason for the observed phenomenon is that layered mud promotes directional coherent reflections while being a weak scatterer. Consequently, a monostatic system with non-vertical inclination on a flat seabed does not receive the highly directional reflected energy (reflection loss), thus suppressing the layer reverberation, whereas the buried cable represents an omnidirectional scatterer. Such a scattering behaviour is promoted by the acoustic regime of the experiment performed with a similar size of the sonar target (cable diameter $0.1 \mathrm{~m}$ ) and an acoustic wavelength of $0.1 \mathrm{~m}$ (approximated by the ratio of $1,500 \mathrm{~m} \mathrm{~s}^{-1}$ sound velocity and $15 \mathrm{kHz}$ signal).

Several models - e.g. the APL-UW composite roughness model of Jackson et al. (1986) — valid for the $10-100 \mathrm{kHz}$ range predict the backscatter angular response for a monostatic setup. Therein, the backscattered strength is modelled by the sum of sea bottom interface reflection, surface roughness scattering and contributions from the subbottom (sediment volume scattering). The Jackson et al. (1986) model predicts the most pronounced backscatter strength decrease below $5^{\circ}$ incidence if the seabed surface roughness spectrum is very small compared to the acoustic wavelength (see Jackson et al. 1986, their Fig. 6, $\alpha=0.5$ ). which apparently is the case for geological layers within mud. The underlying glacial-till interface, however, is rather characterized by a rough surface (Feldens et al. 2015). This explains the remaining relatively strong backscattering of the till even at higher incidence. Similar results showing the most pronounced backscatter decay below $5^{\circ}$ are provided by Sternlicht and deMoustier (2003). who modelled the angular response for clay. Consequently, the results presented in Figs. 3 and 4 with strongest decrease of $\sigma_{\mathrm{w}}$ between $0^{\circ}$ and $3^{\circ}$ qualitatively match current model predictions.

\section{Ideal incidence for cable detection}

The detection performance of the buried cable was determined for a range between $0^{\circ}$ and $60^{\circ}$ incidence to evaluate the ideal angle. The data suggest a maximum SNR at $40^{\circ}$ (Fig. 4c) representing the ideal incidence for cable detection. However, it has to be noted that the cable echo pattern size estimate, which influences the SNR, was conservative with a high threefold standard deviation threshold for contouring and pattern size assessments. Visually, the cable-related backscatter strength anomalies can be detected at lower backscatter values (i.e. outside the contour line, see Fig. 3a, right panels) and appear very pronounced at $15^{\circ}, 30^{\circ}, 45^{\circ}$ and $60^{\circ}$.

If mechanical rotation is not available - e.g. when using a hull-mounted echosounder system-it is suggested to enhance acoustic imaging of shallow buried targets by electronic beam steering available up to $\pm 15^{\circ}$ with the parametric echosounder. Figure 3 clearly shows that the majority of layer reverberations disappear beyond $3^{\circ}$ incidence. Consequently, significant enhancement in buried target detection by removing layer reverberation is feasible without mechanical adaptations using arrayed echosounders with beam-steering abilities.

Future studies should investigate how the approach works at angles beyond $60^{\circ}$. Maguer et al. (2000) present promising sub-bottom detection feasibility even beyond the critical angle in sand using a parametric system. The present study site is characterized by mud having slower sound velocity than the seawater (Richardson and Briggs 1996; Schneider von Deimling et al. 2013). In this case, no critical angle occurs; instead, all energy is transmitted at the so-called angle of intromission (Jackson et al. 1986). It is suggested that the resulting enhanced acoustic sub-bottom transmission might support buried target detection at incidence beyond $60^{\circ}$. 


\section{Cable echo pattern size}

Without sediment sampling, ocean bottom seismometer measurements and modelling, it is only possible to speculate about the observed cable echo pattern size evolution with increasing incidence. The horizontal increase (number of pings with cable detection) is attributed to refraction of the transmitted wave and a large receive footprint (Fig. 2). It is hypothesized that the incident wave will partly travel as a refracted wave in the deeper sediment, normally having higher seismic velocities. If the refracted wave hits the cable, then it will cause scattering. Although the narrow transmitted beam may not insonify the cable directly, a propagating refracted wave can cause scattering outside of the transmit beam, while the cable backscatter induced by the refracted wave can be received via the broad receive beam of the parametric echosounder (Fig. 2). The vertical increase (travel time) coincides with the calculated vertical spreading of the footprint. It is hence likely caused by the increased footprint in cross-track direction caused by the inclination of the transmitted beam.

\section{Detection performance}

The detection performance of the cable in the mud was analysed for all survey lines crossing the cable and achieved $86 \%$, verified by the comparison of the number of vessel tracks crossing the known cable route and the number of detected cable echo patterns (Table 1). False detections may be caused by boulders which are widespread in glacial till (Feldens et al. 2015). However, their occurrence is highly unlikely within the mud in which the cable is buried, as Kiel Fjord represents a low-energy environment (Schwarzer and Themann 2003) and dropstones are not expected due to the absence of local glaciers during the Holocene (Björck 1995). The SNR increases towards higher incidence, where accuracies for bottom detection of the seafloor surface and geolocation are reduced. A possible solution for this shortcoming may arise at intermediate incidence $\left(\sim 30^{\circ}\right)$. At intermediate incidence, the SNR is relatively high compared to the $0^{\circ}$ case (Fig. 4c) while the seafloor surface layer is still visible in the echograms. Thus, the surface echoes can serve as a reference layer in terms of burial depth determination of an object by a geometric ray path and sound velocity approximation.

Currently, magnetometers are the most commonly employed systems for cable detection. However, use of fibre optic communication cables are increasing. Such cables lack a metal core and are not detectable with magnetometers. Leighton and Evans (2008) simulated the case of a cable without a metal core and applied a bistatic system for acoustic detection. They found the acoustic detection feasible with a best incidence of $33^{\circ}$ in sandy sediment, thus supporting the present approach of enhanced acoustic detection of a buried sea cable.

\section{Conclusions}

The study evaluates how non-vertical echosounding reduces the backscatter strength from the seafloor and layered subbottom mud, and reveals that the reduction is substantial already at $3 \pm 0.5^{\circ}$ incidence. We termed this effect layerreverberation loss and consider it poorly constrained in the geophysical community, although the present study demonstrates that it highly affects the resulting acoustic images and interpretation of the data. Unawareness of small inclination misalignments may easily arise by, for example, a slight transducer installation offset or any overlooked seabed surface slope. The present data suggest that such offsets would have wide implications for geological sub-bottom surveying and interpretation.

In regard to acoustic sub-bottom target detection, this study shows that a cable of $0.1 \mathrm{~m}$ diameter buried 1-2 $\mathrm{m}$ below seafloor can be clearly detected due to layer-reverberation loss with inclined parametric sonar. We foresee a large potential using the presented mechanic or electronic sound inclination approach with reasonably small survey platforms for enhanced sub-bottom classification and to better detect shallow buried acoustic scatterers like cables, pipelines, stones, dumping material (mines, waste), submerged shipwrecks, archaeological settlement remains, manganese nodules and shallow gas.

The effect of layer-reverberation loss by inclined echosounding can be promoted in any sedimentary settings dominated by layering and especially in any well-sorted mud. Those occur not only in the Baltic Sea but also widely
Table 1 Information on cable crossings, detections and specific quantities derived from echograms presented in Fig. 4. ( $s t b$ starboard, $m s$ millisecond, $S N R$ signal-to-noise ratio)

\begin{tabular}{llllll}
\hline $\begin{array}{l}\text { Inclination } \\
\left({ }^{\circ}\right)\end{array}$ & $\begin{array}{l}\text { Number of } \\
\text { crossings }\end{array}$ & Detections & $\begin{array}{l}\text { Echo pattern size } \\
(\mathrm{ms} \text { * pings) }\end{array}$ & $\begin{array}{l}\text { Max. cable } \\
\text { backscatter }\end{array}$ & SNR \\
\hline 0 & 8 & 8 & $6.91 \pm 1.98$ & $1,587.01 \pm 227.46$ & $0.16 \pm 0.05$ \\
$15 \mathrm{stb}$ & 14 & 11 & $10.65 \pm 1.72$ & $1,740.35 \pm 514.15$ & $0.35 \pm 0.05$ \\
$30 \mathrm{stb}$ & 9 & 9 & $31.35 \pm 4.45$ & $327.80 \pm 23.26$ & $0.40 \pm 0.05$ \\
$45 \mathrm{stb}$ & 19 & 16 & $39.09 \pm 3.36$ & $255.05 \pm 26.81$ & $0.42 \pm 0.04$ \\
$60 \mathrm{stb}$ & 15 & 12 & $69.77 \pm 7.27$ & $96.10 \pm 11.69$ & $0.36 \pm 0.05$ \\
\hline
\end{tabular}


on continental shelves, slopes as well as in the deep sea, where an inclined parametric sonar approach on an autonomous underwater vehicle could give rise to pioneering survey and research applications.

Acknowledgements The study was funded by the Marine Technology Platform (MaTeP) under the umbrella of FUTURE OCEAN receiving funds from the German Research Foundation (DFG). Additional support was provided by the FUTURE OCEAN project CP1207. We highly appreciate the collaboration with our project partner Embient $\mathrm{GmbH}$ (today KONGSBERG Maritime Embient $\mathrm{GmbH}$ ). We would like to thank the captain, officers and crew aboard R/V LITTORINA. Furthermore, we acknowledge the contribution of excellent student work by Eike Barnefske (Hafen City University, Hamburg, Germany) and Isabell Mücke (University Kiel, Germany). Last but not least, we very much appreciate the thorough review by Geoffroy Lamarche, comments from an anonymous reviewer and proof reading by Christian Berndt.

\section{Compliance with ethical standards}

Conflict of interest The authors declare that there is no conflict of interest with third parties.

Open Access This article is distributed under the terms of the Creative Commons Attribution 4.0 International License (http:// creativecommons.org/licenses/by/4.0/), which permits unrestricted use, distribution, and reproduction in any medium, provided you give appropriate credit to the original author(s) and the source, provide a link to the Creative Commons license, and indicate if changes were made.

\section{References}

Björck S (1995) A review of the history of the Baltic Sea, 13.0-8.0 ka BP. Quat Int 27:19-40

Feldens P, Diesing M, Schwarzer K, Heinrich C, Schlenz B (2015) Occurrence of flow parallel and flow transverse bedforms in Fehmarn Belt (SW Baltic Sea) related to the local palaeomorphology. Geomorphology 231:53-62

Hinz K, Kögler F, Richter I, Seibold E (1971) Reflexionsseismische Untersuchungen mit einer pneumatischen Schallquelle und einem Sedimentecholot in der westlichen Ostsee. Meyniana 21:17-24

Jackson D, Richardson M (2007) High-frequency seafloor acoustics. Springer, Heidelberg

Jackson DR, Winebrenner DP, Ishimaru A (1986) Application of the composite roughness model to high-frequency bottom backscattering. J Acoust Soc Am 79(5):1410-1422
Jans W, Reuter M, Behringer S, Bohlmann S (2012) Probing the seafloor in order to find dumped ammunition and other hazardous materials. Springer, Berlin, pp 315-326

Leighton TG, Evans RCP (2008) The detection by sonar of difficult targets (including centimetre-scale plastic objects and optical fibres) buried in saturated sediment. Appl Acoust 69(5):438-463

Maguer A, Fox WL, Schmidt H, Pouliquen E, Bovio E (2000) Mechanisms for subcritical penetration into a sandy bottom: experimental and modeling results. J Acoust Soc Am 107(3):1215-1225

Mitchell NC (1993) A model for attenuation of backscatter due to sediment accumulations and its application to determine sediment thicknesses with GLORIA sidescan sonar. J Geophys Res Solid Earth 98(B12):22477-22493

Novikov BK, Rudenko OV, Timoshenko VI (1987) Nonlinear underwater acoustics. American Institute of Physics, College Station

Piper JE (2001) Buried target detection with a synthetic aperture sonar. In: Proc OCEANS 2001, MTS/IEEE Conference and Exhibition, vol 1, p 220-224

Richardson MD, Briggs KB (1996) In situ and laboratory geoacoustic measurements in soft mud and hard-packed sand sediments: implications for high-frequency acoustic propagation and scattering. GeoMar Lett 16(3):196-203

Rostek F, Spieß V, Bleil U (1991) Parasound echosounding: comparison of analogue and digital echosounder records and physical properties of sediments from the Equatorial South Atlantic. Mar Geol 99(1):118

Schneider von Deimling J, Weinrebe W, Tóth Z, Fossing H, Endler R, Rehder G, Spieß V (2013) A low frequency multibeam assessment: spatial mapping of shallow gas by enhanced penetration and angular response anomaly. Mar Pet Geol 44:217-222

Schock SG (2008) Synthetic aperture 3D buried object imaging. Underw Technol 27(4):185-193

Schwarzer K, Themann S (2003) Sediment distribution and geological build up of Kiel Fjord (Western Baltic Sea). Meyniana 55:91-115

Sternlicht DD, deMoustier CP (2003) Time-dependent seafloor acoustic backscatter (10-100 kHz). J Acoust Soc Am 114(5):2709-2725

Stockwell JW (1999) The CWP/SU: Seismic Unix package. Comput Geosci 22:415-419

Szender S, Kosalos J (1997) Development and feasibility testing of an acoustic buried cable detection system. In: Proc OCEANS'97, MTS/IEEE Conference, vol 2, p 913-920

Vardy ME, Dix JK, Henstock TJ, Bull JM, Gutowski M (2008) Decimeter-resolution 3D seismic volume in shallow water: a case study in small-object detection. Geophysics 73(2):B33-B40

Wunderlich J (2007) Mobile parametric sub-bottom profiler system for shallow and medium depth applications. J Acoust Soc Am 122(5): 2983

Wunderlich J, Wendt G, Müller S (2005) High-resolution echo-sounding and detection of embedded archaeological objects with nonlinear sub-bottom profilers. Mar Geophys Res 26(2-4):123-133 